\title{
Cooperative binding of the red clover necrotic mosaic virus movement protein to single-stranded nucleic acids
}

\author{
T. A. M. Osman, R. J. Hayes and K. W. Buck* \\ Department of Biology, Imperial College of Science, Technology and Medicine, London SW7 2BB, U.K.
}

The movement protein of red clover necrotic mosaic dianthovirus was produced in Escherichia coli using an expression vector. Gel retardation analysis and u.v. cross-linking studies showed that the movement protein bound cooperatively to ssRNA and ssDNA, but not to dsDNA. Binding competition experiments established that the movement protein bound to ssRNA and ssDNA with similar affinities and that the binding was not sequence-specific in the experimental conditions employed. A truncated movement protein lacking the C-terminal 88 amino acids was also shown to bind to SsRNA.

\section{Introduction}

Systemic infection of a plant by a virus requires two forms of spread from the cells initially infected: shortdistance movement from cell to cell probably via plasmodesmata and long-distance movement via the vascular system (reviewed by Hull, 1989; Robards \& Lucas, 1990; Atabekov \& Taliansky, 1990; Maule, 1991). Virus cell-to-cell movement is not a passive process but requires virus-encoded movement proteins. The movement protein of tobacco mosaic tobamovirus (TMV) is located in the plasmodesmata of virus-infected plants (Tomenius et al., 1987) or plants transgenic for the movement protein (Atkins et al., 1991). In such plants the molecular size exclusion limit of the plasmodesmata is increased (Wolf et al., 1989; Deom et al., 1990). The discovery that the TMV movement protein binds cooperatively to single-stranded nucleic acids (Citovsky et al., 1990) led to the suggestion that it has two functions, increasing the permeability of plasmodesmata and forming an unfolded RNA-movement protein complex that is able to move through the modified plasmodesmata. The subsequent finding that the putative movement protein (the gene I protein) of cauliflower mosaic caulimovirus (CaMV) also binds to single-stranded nucleic acids led to speculation that movement of singlestranded nucleic acid-movement protein complexes through plasmodesmata may be a general mechanism for spread of plant viruses from cell to cell (Citovsky et al., 1991). However, before this generalization can be proved, studies on the movement proteins of a range of diverse plant viruses will be needed.

Red clover necrotic mosaic dianthovirus (RCNMV) has a genome of two positive-sense ssRNA components,
RNA $1(3.9 \mathrm{~kb})$ and RNA $2(1.4 \mathrm{~kb})$ (Lommel et al., 1988; Xiong \& Lommel, 1989). The RCNMV movement protein is encoded by RNA 2 (Lommel et al., 1988; Osman et al., 1991a) and no significant amino acid sequence homology with the movement protein of TMV or the gene I protein of $\mathrm{CaMV}$ could be detected using a modified FASTA programme (Pearson \& Lipman, 1988). In the present paper, we have investigated the ability of the RCNMV movement protein to bind to nucleic acids.

\section{Methods}

Expression and purification of the RCNMV movement protein. The recombinant plasmid pTM34-210, containing a full-length cDNA copy of RNA 2 of RCNMV isolate TpM-34 flanked by a phage T7 promoter cloned into pUC19, has been described previously (Osman et al., 1991 b). An $\mathrm{Nde}$ site was introduced at the translational initiation codon of the movement protein gene by in vitro mutagenesis (Kunkel et al., 1987) using the oligonucleotide AGGTAGGTTTCATATGGCTATTC. A DNA fragment containing the movement protein coding region and the $3^{\prime}$ untranslated region was then excised using $N d e I$ and BamHI and cloned into the corresponding sites of the T7 RNA polymerase vector pET3a (Rosenberg et al., 1987) to give pETMP. The NdeI restriction site of $\mathrm{pET} 3 \mathrm{a}$ contains the translational initiation codon so that the pETMP plasmid expresses the RCNMV movement protein without alterations to the coding sequence. The plasmid pETMP was then transformed into Escherichia coli strain BL21(DE3)pLysE (Studier \& Moffatt, 1986). Induction of movement protein synthesis and purification of the movement protein were as described by Citovsky et al. (1990) for the TMV movement protein, except that after induction the cell pellet was lysed by sonication (MSE Soniprep 150; amplitude $10 \mu \mathrm{m} ; 4 \mathrm{~min}$ ). Similar methods were used to produce and purify a truncated movement protein starting with the recombinant plasmid pTM341-210 (Osman et al., 1991 b). 
Preparation of RNA probes. Labelled RNA probes, corresponding to different lengths of RCNMV RNA 2, were prepared by in vitro transcription of pTM34-201 with T7 RNA polymerase in the presence of [ $\left.{ }^{32} \mathrm{P}\right] \mathrm{UTP}$ as described previously (Osman et al., 1991 b). Probes of 387 nucleotides (nt), $1082 \mathrm{nt}$ and $1448 \mathrm{nt}$ (full-length RNA 2) were obtained by linearization of the plasmid with $T$ th111I, BstBI or PstI, respectively, prior to transcription. After transcription, DNA and protein were removed by digestion with RNase-free DNase, phenol extraction and ethanol precipitation.

Preparation of DNA probes, retardation gel electrophoresis, nucleic acid-protein cross-linking by u.v. irradiation and binding competition. These experiments were carried out essentially as described by Citovsky et al. (1990)

\section{Results}

\section{Expression and purification of the RCNMV movement} protein

The RCNMV movement protein was expressed in E. coli cells carrying plasmid pETMP which contains the coding region of the movement protein linked to a strong bacteriophage $\mathrm{T} 7$ promoter. Induction of expression of the T7 RNA polymerase resulted in the synthesis of a protein with the expected size of the movement protein $\left(M_{\mathrm{r}} 36 \mathrm{~K}\right)$ (Fig. 1, lane 3). The movement protein formed insoluble aggregates which could be separated from the soluble bacterial proteins by centrifugation. However, the movement protein could be solubilized in $4 \mathrm{M}$-urea and remained soluble after removal of the urea. Thus, the RCNMV movement protein behaved similarly to both the TMV movement protein and the CaMV gene I protein when these were expressed in $E$. coli using similar vectors (Citovsky et al., 1990, 1991). The purified RCNMV movement protein gave a single band in SDSPAGE (Fig. 1, lane 4). Similar methods were used to express and purify a truncated movement protein $\left(M_{\mathrm{r}}\right.$ $30 \mathrm{~K}$ ) using an RNA 2 cDNA clone from RCNMV mutant TpM-341 (Osman et al., 1991 b) (Fig. 1, lane 5).

\section{The RCNMV movement protein binds to single-stranded nucleic acids}

To study the potential of the RCNMV movement protein to bind to ssRNA, a ${ }^{32} \mathrm{P}$-labelled ssRNA corresponding to the $5^{\prime} 387 \mathrm{nt}$ of RCNMV RNA 2 was synthesized by in vitro transcription. After incubation of this RNA with the movement protein, the RNA was cross-linked to the protein by u.v. irradiation and unbound RNA was removed by digestion with RNase. Analysis of the protein by SDS-PAGE and autoradiography revealed a band with an apparent $M_{\mathrm{r}}$ of $38 \mathrm{~K}$ i.e. in the position expected for the movement protein crosslinked to a small number of nucleotides (Fig. 2a). A strong band was detected when the incubation was

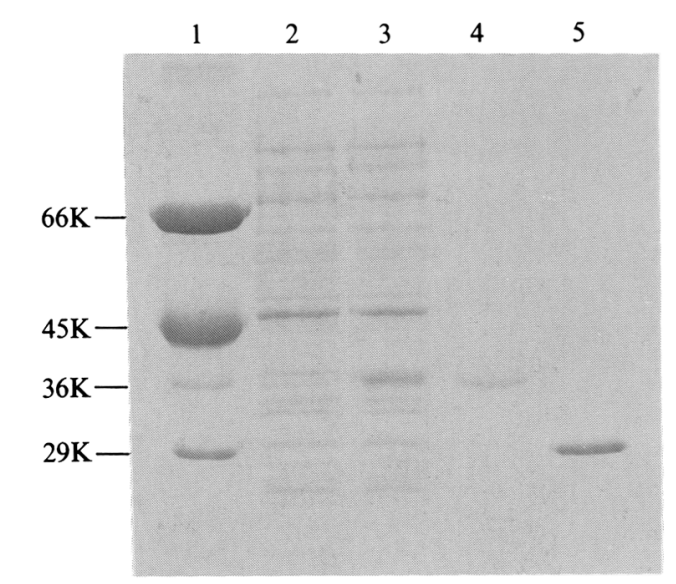

Fig. 1. Analysis of the expression and purification of the RCNMV movement protein by SDS-PAGE. Lane 1, marker proteins; lane 2, protein from uninduced $E$. coli (pETMP); lane 3, protein from induced E. coli (pETMP); lane 4, purified RCNMV movement protein; lane 5 , purified truncated RCNMV movement protein. The gel was stained with Coomassie blue R250. The $M_{\mathrm{r}}$ values of marker proteins (BSA, $66 \mathrm{~K}$; ovalbumin, $45 \mathrm{~K}$; glyceraldehyde 3-phosphate dehydrogenase, $36 \mathrm{~K}$; carbonic anhydrase, $29 \mathrm{~K}$ ) are shown on the side of the gel.

carried out in $0.2 \mathrm{M}-\mathrm{NaCl}$ or $0.4 \mathrm{M}-\mathrm{NaCl}$ (Fig. $2 a$, lanes 1 and 2), a weaker band was found at $0.6 \mathrm{M}-\mathrm{NaCl}$ (Fig. $2 a$, lane 3) and no band could be detected at $0.8 \mathrm{M}-\mathrm{NaCl}$ or $1.0 \mathrm{M}-\mathrm{NaCl}$ (Fig. $2 a$, lanes 4 and 5). This indicates that the movement protein-RNA complex was stable at 0.2 $\mathrm{M}-\mathrm{NaCl}$ and $0.4 \mathrm{M}-\mathrm{NaCl}$, was partially dissociated at 0.6 $\mathrm{M}-\mathrm{NaCl}$ and completely dissociated at $0.8 \mathrm{M}-\mathrm{NaCl}$ and $1.0 \mathrm{M}-\mathrm{NaCl}$. No band could be detected when the incubation was carried out in the presence of 1000 -fold excess unlabelled ssRNA (Fig. 2a, lane 7), after incubation with proteinase $\mathrm{K}$ (Fig. $2 a$, lane 6) or when the u.v. irradiation step was omitted (Fig. 2a, lane 8). The same method was used to demonstrate binding of the movement protein to an ssRNA corresponding to the $5^{\prime} 1082 \mathrm{nt}$ of RCNMV RNA 2 and to full-length RCNMV RNA 2 (1448 nt) (Fig. 2b, lanes 3 and 4).

To ensure that the observed binding was not due to an undetected $E$. coli protein in the movement protein preparation, two controls were carried out. In the first, an equivalent protein preparation from $E$. coli transformed with pET3a lacking the RCNMV sequences was made. No bands could be detected in SDS-PAGE after Coomassie blue staining of the free protein or after carrying out the u.v. cross-linking assay with the ${ }^{32} \mathrm{P}-$ labelled $387 \mathrm{nt}$ RNA in $0.2 \mathrm{M}-\mathrm{NaCl}$. In the second, binding to a truncated movement protein, which lacks the C-terminal 88 amino acids of the full-length movement protein and has an $M_{\mathrm{r}}$ of $30 \mathrm{~K}$ (Osman et al., $1991 b$ ), was demonstrated. In the u.v. cross-linking assay, a band of apparent $M_{\mathrm{r}} 32 \mathrm{~K}$ was formed with this truncated movement protein (Fig. $2 b$, lanes 1 and 2). It is 
(a)

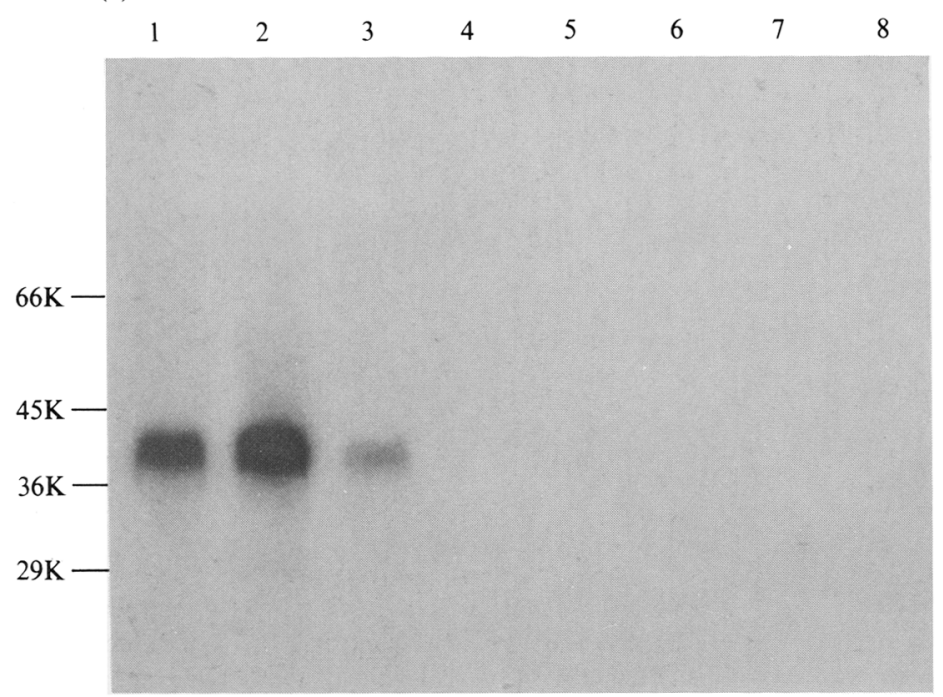

(b)

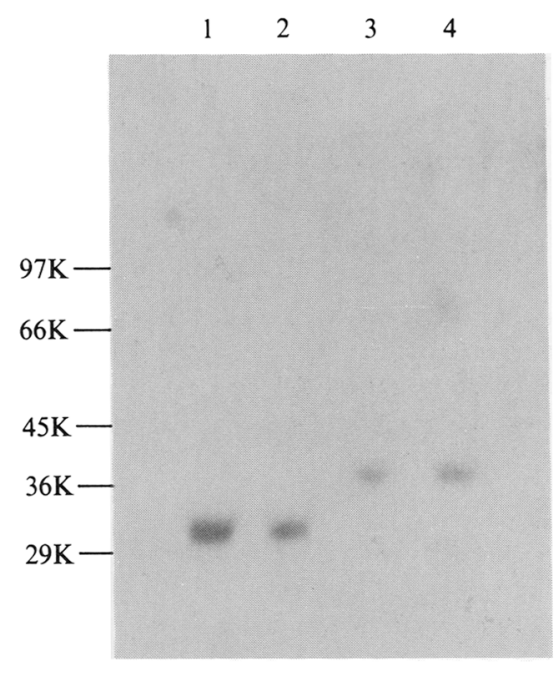

Fig. 2. Analysis of the binding of the RCNMV movement protein to ssRNA by u.v. cross-linking and SDS-PAGE. (a) Effect of NaCl concentration. The RCNMV movement protein $\left(25 \mathrm{ng}\right.$ ) was incubated for $30 \mathrm{~min}$ at $4{ }^{\circ} \mathrm{C}$ with $1.0 \mathrm{ng}$ of ${ }^{32} \mathrm{P}$-labelled $387 \mathrm{nucleotide}$ ssRNA probe and analysed by the u.v. cross-linking assay. Lane $1,0.2 \mathrm{M}-\mathrm{NaCl}$; lane $2,0.4 \mathrm{M}-\mathrm{NaCl} ;$ lane $3,0.6 \mathrm{M}-\mathrm{NaCl} ;$ lane $4,0.8 \mathrm{M}-$ $\mathrm{NaCl}$; lane $5,1.0 \mathrm{M}-\mathrm{NaCl}$; lane 6 , incubation in $0.2 \mathrm{M}-\mathrm{NaCl}$ followed by treatment with proteinase $\mathrm{K}(1 \mathrm{mg} / \mathrm{ml})$ at $37^{\circ} \mathrm{C}$ for $30 \mathrm{~min} ;$ lane 7, incubation in $0 \cdot 2 \mathrm{M}-\mathrm{NaCl}$ in the presence of a 1000-fold excess of unlabelled RCNMV RNA; lane 8, incubation in $0.2 \mathrm{M}-\mathrm{NaCl}$, but omission of the u.v. irradiation step. (b) Binding to longer ssRNAs. Full-length (lanes 3 and 4) or truncated (lanes 1 and 2) RCNMV movement protein ( $25 \mathrm{ng}$ ) was incubated for $30 \mathrm{~min}$ at $4{ }^{\circ} \mathrm{C}$ in $0.2 \mathrm{M}-\mathrm{NaCl}$ with $1.0 \mathrm{ng}$ of ${ }^{32} \mathrm{P}$-labelled $1082 \mathrm{nt}$ RNA (lanes 1 and 3) or RCNMV RNA 2 (lanes 2 and 4). Marker proteins are as in Fig. 1, with the addition of phosphorylase b $\left(M_{\mathrm{r}} 97 \mathrm{~K}\right)$.

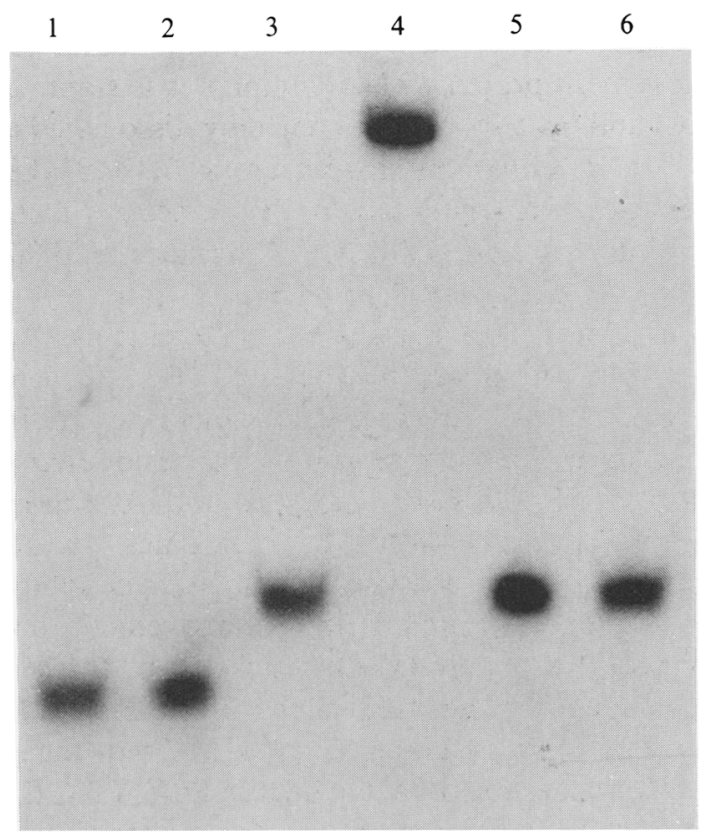

Fig. 3. Gel retardation analysis of the binding of the RCNMV movement protein to DNA. Lane 1, dsDNA probe incubated with the RCNMV movement protein; lane 2, dsDNA probe; lane 3, ssDNA probe incubated with the RCNMV movement protein, followed by incubation with proteinase $\mathrm{K}(1 \mathrm{mg} / \mathrm{ml})$ for $30 \mathrm{~min}$ at $37^{\circ} \mathrm{C}$; lane 4 , ssDNA probe incubated with the RCNMV movement protein; lane 5 , ssDNA probe incubated with the RCNMV movement protein in the presence of a 1000-fold excess of unlabelled ssDNA; lane 6, ssDNA probe. Incubations were at $4{ }^{\circ} \mathrm{C}$ for $30 \mathrm{~min}$ in $0.2 \mathrm{M}-\mathrm{NaCl}$ with $25 \mathrm{ng}$ of movement protein and $1.0 \mathrm{ng}$ of ${ }^{32} \mathrm{P}$ end-labelled probe. clear that the electrophoretic mobilities of the covalently cross-linked protein-nucleotide complexes (Fig. 2b) correlate with those of the free full-length and truncated movement proteins (Fig. 1), showing that the binding is the activity of the movement proteins and not that of a protein contaminant.

To ensure that the assay conditions did not promote indiscriminate binding of proteins to single-stranded nucleic acids, binding of the $E$. coli maltose-binding protein (Duplay et al., 1984) to the above ssRNAs in $0 \cdot 2$ $\mathrm{M}-\mathrm{NaCl}$ was studied by the u.v. crossing-linking method. No binding could be demonstrated (data not shown).

The ability of the RCNMV movement protein to bind to ssDNA was shown by gel retardation analysis. A 298 bp HaeIII restriction fragment of pUC18 (YanischPerron et al., 1985) was end-labelled with ${ }^{32} \mathbf{P}$, denatured and incubated with the RCNMV movement protein in $0.2 \mathrm{M}-\mathrm{NaCl}$. Electrophoresis in a polyacrylamide gel, followed by autoradiography, showed a single band with a mobility (Fig. 2, lane 4) considerably slower than that of the free ssDNA (Fig. 3, lane 6). When the incubation was carried out in the presence of a 1000-fold excess of unlabelled ssDNA, or when the complex was treated with proteinase $\mathrm{K}$, a band corresponding to only the free ssDNA was detected (Fig. 3, lanes 5 and 3). No retardation was observed when the movement protein was incubated with the 298 bp dsRNA probe (Fig. 3, compare lanes 1 and 2). 
(a)

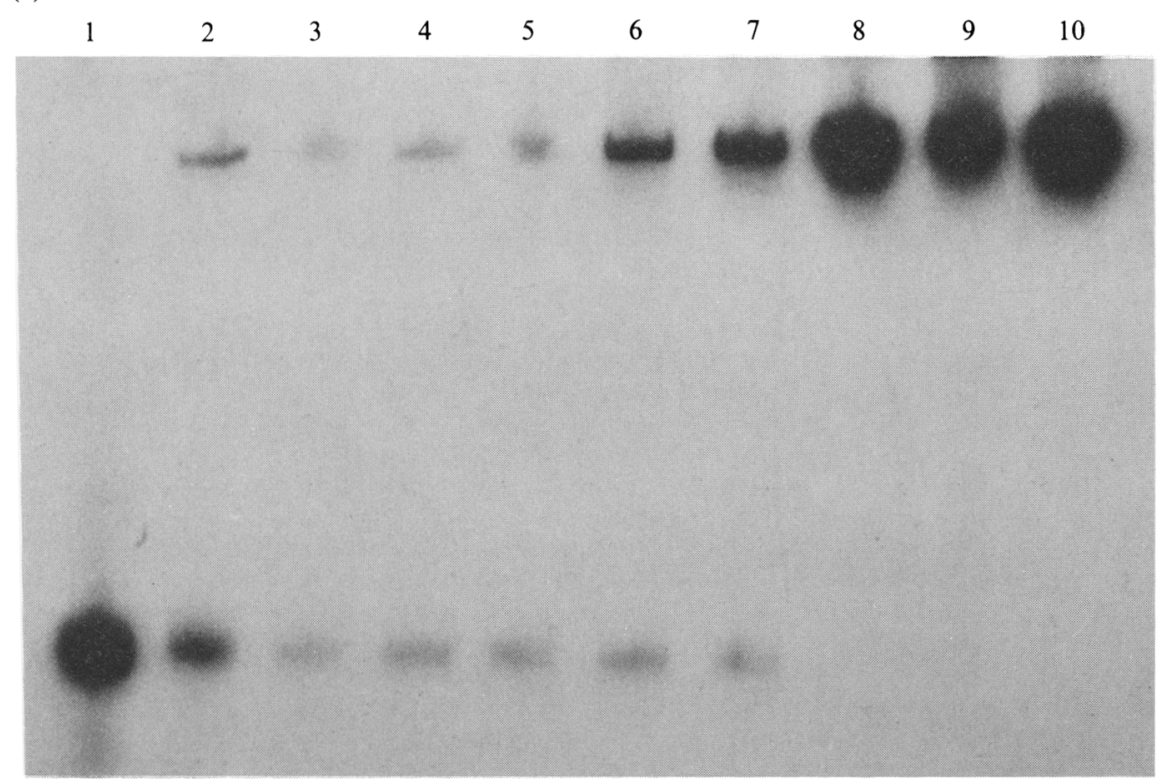

(b)

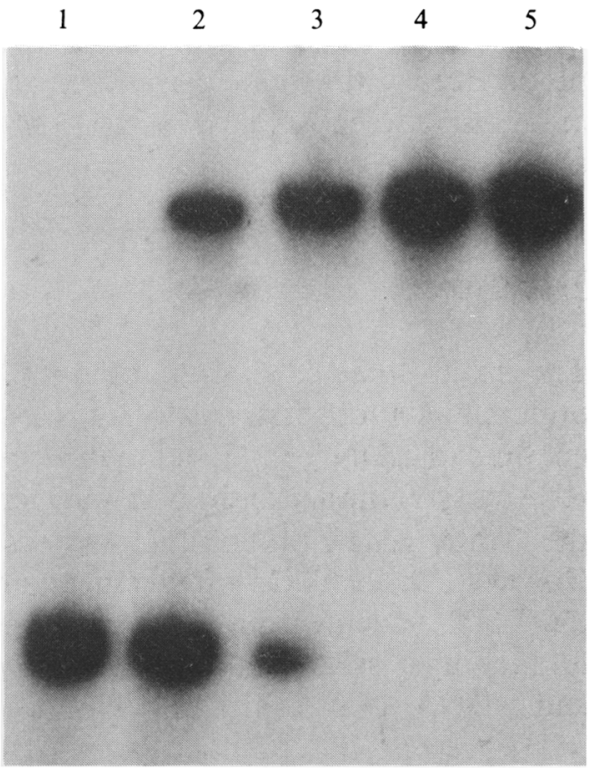

Fig. 4. Cooperative binding of the RCNMV movement protein to ssRNA and dsDNA. Increasing amounts of the RCNMV movement protein were incubated with $(a){ }^{32} \mathrm{P}$-labelled $387 \mathrm{nt}$ ssRNA probe $(50 \mathrm{ng})$ or $(b)$ ssDNA probe $(50 \mathrm{ng})$ as in Fig. 3 and analysed by gel retardation analysis. Amounts of protein $(\mu \mathrm{g})$ were $(a)$ lane 1,$0 ;$ lane $2,0.01 ;$ lane $3,0.02 ;$ lane $4,0.05 ;$ lane $5,0.1 ;$ lane $6,0.2 ;$ lane $7 ; 0.5$; lane $8,1 \cdot 0$; lane $9,2 \cdot 0$; lane $10,4 \cdot 0$ or $(b)$ lane 1,0 ; lane $2,0.5$; lane $3,1 \cdot 0$; lane $4,1.5$; lane $5,2.0$.

Binding of the RCNMV movement protein to singlestranded nucleic acids is cooperative

When the ${ }^{32} \mathrm{P}$-labelled $387 \mathrm{nt}$ ssRNA was incubated with increasing amounts of the RCNMV movement protein, followed by PAGE, a band of free RNA and a band of retarded RNA were detected at the lower protein:RNA ratios (Fig. 4a, lanes 2 to 7). However, at higher protein:RNA ratios, only the band of retarded RNA was detected (Fig. $4 a$, lanes 8 to 10). The absence of any bands intermediate between the free and retarded RNA indicates that the binding of the movement protein to this RNA is cooperative. Similar results were obtained with the $1082 \mathrm{nt}$ RNA and full-length RNA 2 (results not shown), and with the $298 \mathrm{nt}$ ssDNA (Fig. $4 b$ ).

Competition of binding of the RCNMV movement protein to different nucleic acids

The u.v. cross-linking method was used to compare the abilities of unlabelled RCNMV RNA (RNA 1, $3889 \mathrm{nt}$; RNA 2, $1448 \mathrm{nt}$ ), TMV RNA (strain L, $6384 \mathrm{nt}$; Ohno et al., 1984) and M13 mpl8 ssDNA (7250 nt, YanischPerron et al., 1985) to compete with labelled RCNMV RNA 2 for binding to the RCNMV movement protein. The results showed that both unlabelled RCNMV RNA and TMV RNA efficiently compete with the labelled RCNMV RNA 2. For both competing RNAs, the intensities of these bands were reduced concurrently with increasing amounts of unlabelled to labelled RNA

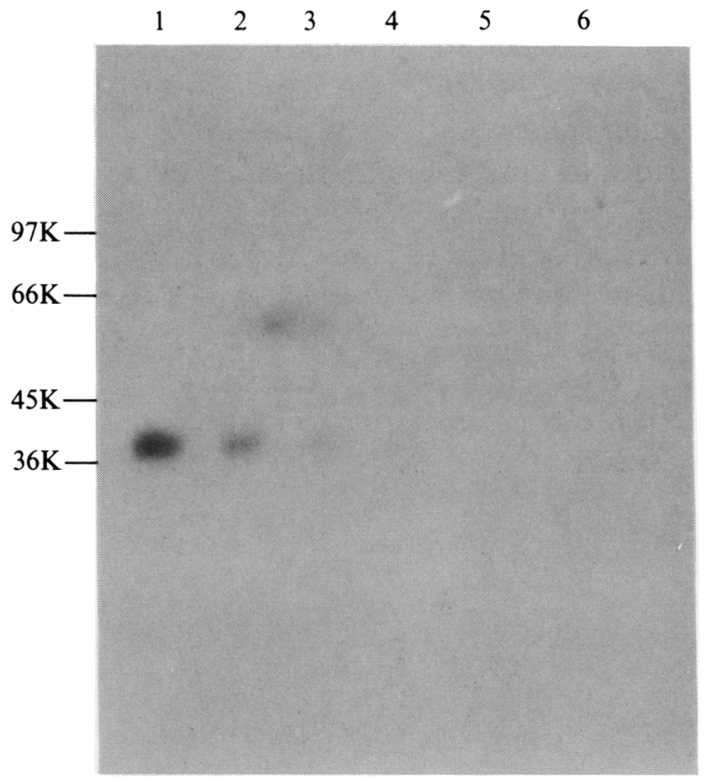

Fig. 5. Competition of binding of the RCNMV and TMV movement proteins to ssR NA analysed by u.v. cross-linking and SDS-PAGE. The RCNMV movement protein $(25 \mathrm{ng})$ was incubated for $30 \mathrm{~min}$ at $4{ }^{\circ} \mathrm{C}$ with $1.5 \mathrm{ng}$ of ${ }^{32} \mathrm{P}$-labelled RCNMV RNA 2 in the presence of increasing amounts of unlabelled TMV-L RNA. The competitor:probe ratios were lane 1, 0; lane 2, 100; lane 3,500; lane 4, 1000; lane 5, 2000; lane 6, 4000. Marker proteins are as in Fig. 1 and 2.

and the bands were no longer detected at a ratio of unlabelled to labelled RNA of $2000: 1$ (shown for TMV RNA in Fig. 5). Essentially similar results were also obtained using M13 ssDNA as a competitor (results not 
shown). Although the data were not quantified, visual inspection of the autoradiographs failed to reveal any pronounced differences in movement protein binding affinities between RCNMV RNA, TMV RNA and M13 ssDNA.

\section{Discussion}

The results obtained show that the RCNMV movement protein binds cooperatively to ssRNA and ssDNA, does not bind to dsDNA and is not sequence-specific. In these respects, it is similar to the TMV movement protein and the CaMV gene I protein (Citovsky et al., 1990, 1991). However, the RCNMV movement protein resembled the TMV movement protein more closely in its affinity for binding to ssRNA and in its ability to bind to ssRNA and ssDNA with similar affinities.

The recent finding that the RCNMV movement protein is located in a cell wall fraction (Osman \& Buck, 1991), combined with the demonstration of its ability to bind cooperatively to ssRNA, is consistent with the model of Citovsky et al. $(1990,1991)$ for movement of viral single-stranded nucleic acid-movement protein complexes through plasmodesmata, although it does not prove it, nor exclude the possibilities of other mechanisms for virus cell-to-cell movement. Nevertheless, the conservation of the ability of the proteins of three diverse plant viruses to bind to single-stranded nucleic acids is interesting, particularly because the RCNMV movement protein is not related perceptibly in primary amino acid sequence to the TMV movement protein or the CaMV gene I protein. It is possible, as suggested by Melcher (1990), that the functions of plant virus movement proteins depend more on their three-dimensional structure than on their overall sequence similarity.

We thank the Agricultural and Food Research Council for a grant (to K.W.B.) and a Fellowship (to R.J.H.).

\section{References}

Atabekov, J. G. \& Taliansky, M. E. (1990). Expression of a plant virus-encoded transport function by different viral genomes. Advances in Virus Research 38, 201-248.

Atkins, D., Hull, R., Wells, B., Roberts, K., Moore, P. \& BeaChy, R. N. (1991). The tobacco mosaic virus 30K movement protein in transgenic plants is localized to plasmodesmata. Journal of General Virology 72, 209-211.

Citovsky, V., Knorr, D., Schuster, G. \& Zambryski, P. (1990). The P30 movement protein of tobacco mosaic virus is a single-strand nucleic acid binding protein. Cell 60, 637-647.
Citovsky, V., KNorR, D. \& Zambr YsKi, P. (1991). Gene I, a potential cell-to-cell movement locus of cauliflower mosaic virus, encodes an RNA-binding protein. Proceedings of the National Academy of Sciences, U.S.A. 88, 2476-2480.

Deom, C. M., Schubert, K. R., Wolf, S., Holt, C. A., Lucas, W. J. \& BEACHY, R. N. (1990). Molecular characterization and biological function of the movement protein of tobacco mosaic virus in transgenic plants. Proceedings of the National Academy of Sciences, U.S.A. 87, 3284-3288.

Duplay, P., Bedovelle, H., Fowler, A., Zabin, I., Saurin, W. \& HofNUNG, N. (1984). Sequence of the mal-E gene and of its product, the maltose-binding protein of Escherichia coli K12. Journal of Biological Chemistry 259, 10606-10613.

HuLL, R. (1989). The movement of viruses in plants. Annual Review of Phytopathology 27, 213-240.

KUNKEL, T. A., RoBerTs, J. D. \& ZaKour, R. A. (1987). Rapid and efficient site-specific mutagenesis without phenotypic selection. Methods in Enzymology 154, 367-382.

LOMMel, S. A., Weston-FinA, M. \& Lomonossoff, G. P. (1988). The nucleotide sequence and gene organization of red clover necrotic mosaic virus RNA-2. Nucleic Acids Research 16, 8587-8601.

Maule, A. J. (1991). Virus movement in infected plants. Critical Reviews in Plant Sciences 9, 457-473.

Melcher, U. (1990). Similarities between putative transport proteins of plant viruses. Journal of General Virology 71, 1009-1018.

OhNo, T., Aoyagi, M., Yamanishi, Y., Saito, H., IKawa, S., Meshi, T. \& OKADA, Y. (1984). Nucleotide sequence of the tobacco mosaic virus (tomato strain) genome and comparison with the common strain genome. Journal of Biochemistry 96, 1915-1923.

Osman, T. A. M. \& BuCK, K. W. (1991). Detection of the movement protein of red clover necrotic mosaic virus in a cell wall fraction from infected Nicotiana clevelandii plants. Journal of General Virology 72, 2853-2856.

Osman, T. A. M., Miller, S. J., Marriott, A. C. \& Buck, K. W. (1991 a). Nucleotide sequence of RNA 2 of a Czechoslovakian isolate of red clover necrotic mosaic virus. Journal of General Virology 72, 213-216.

Osman, T. A. M., Ingles, P. J., Miller, S. J. \& Buck, K. W. (1991 b). A spontaneous red clover necrotic mosaic virus mutant with a truncated movement protein. Journal of General Virology 72, 17931800.

Pearson, W. R. \& Lipman, D. J. (1988). Improved tools for biological sequence comparison. Proceedings of the National Academy of Sciences, U.S.A. 85, 2444-2448.

Robards, A. W. \& LUCAS, W. J. (1990). Plasmodesmata. Annual Review of Plant Physiology and Plant Molecular Biology 41, 369-419.

Rosenberg, A. H., Lade, B. N., Chui, D.-S., Liu, S.-W., DunN, J. J. \& StUDIER, F. W. (1987). Vectors for selective expression of cloned DNAs by T7 RNA polymerase. Gene 56, 125-135.

Studier, F. W. \& MoffatT, B. A. (1986). Use of bacteriophage T7 RNA polymerase to direct selective high-level expression of cloned genes. Journal of Molecular Biology 189, 113-130.

Tomenius, K., ClaphaM, D. \& MeshI, T. (1987). Localization by immunogold cytochemistry of the virus-coded $30 \mathrm{~K}$ protein in plasmodesmata of leaves infected with tobacco mosaic virus. Virology 160, 363-371.

Wolf, S., Deom, C. M., Beachy, R. N. \& Lucas, W. J. (1989). Movement protein of tobacco mosaic virus modifies plasmodesmatal size exclusion limit. Science 246, 377-379.

XIONG, Z. \& LOMMEL, S. A. (1989). The complete nucleotide sequence and genome organization of red clover necrotic mosaic virus RNA-1. Virology 171, 543-554.

Yanisch-PerRon, C., Vieira, J. \& Messing, J. (1985). Improved M13 phage cloning vectors and host strains: nucleotide sequences of the M13 mp18 and pUC19 vectors. Gene 33, 103-119.

(Received 26 July 1991; Accepted 18 October 1991) 